\title{
A IDEIA DE AUTONOMIA EM LOCKE. FELICIDADE E JUSNATURALISMO. DISPOSITIVO METAFÍSICO-RELIGIOSO E SECULARIZAÇÃO.
}

\author{
THE IDEA OF AUTONOMY IN LOCKE. HAPPINESS AND NATURAL LAW. \\ METAPHYSICAL APPARATUS AND SECULARIZATION.
}

Manuel Afonso Costa*

RESUMO: É verdade que Locke oscila entre uma tradição intelectualista e realista que lhe vem de Hooker e uma tradição voluntarista, afim da sua própria formação religiosa. Num plano, o da fundamentação última das obrigações, triunfa a segunda, mas no plano das decisões práticas, Locke comporta-se como um puro racionalista.A grande originalidade de Locke reside no modo ecléctico como ele utiliza os conceitos gregos de phronesis, sophrosyne e epoché, um essencialmente epicurista e aristotélico e o outro proveniente da cultura do cepticismo; e, o que é talvez o mais importante ainda, o modo como ele integra nesta preocupação, a da suspensão do juízo e da acção, o conceito de «uneasiness».

PALAVRAS-CHAVE: «Uneasiness». Felicidade. Heteronomia. Remunerações e Penas.

ABSTRACT: It is true that Locke is between an intellectual and realist tradition that comes from Hooker and a voluntarist tradition, akin to his own religious upbringing. In the plan of the ultimate grounding of the bonds, the second triumph, but in terms of practical decisions, Locke behaves like a pure rationalist. The great originality of Locke lies in the eclectic way as he uses the Greeks concepts of phronesis, sophrosyne and epoché, the first and the second, both essentially Aristotelian and Epicurean and the other from the culture of skepticism, and, what is perhaps most importantly, how it integrates this concern, the suspension of court action and the concept of uneasiness.

KEYWORDS: «Uneasiness». Happiness. Heteronomy. Rewards and Punishments.

* Doutorado pela Faculdade de Ciências Sociais e Humanas (FCSH) da Universidade Nova de Lisboa (UNL), na área de História e Teoria das Ideias, na especialidade de História e Teoria dos Paradigmas. Membro do Centro de Estudos e Desenvolvimento, Direito e Sociedade (CEDIS) da Faculdade de Direito (FD) da Universidade Nova de Lisboa (UNL). 


\section{INTRODUÇÃ̃O}

A primeira sensação que se tem quando se passa pela primeira vez pelo pensamento de Locke e, em particular, no que diz respeito às questões jurídicas, através dos Questions Concerning the Laws of Nature, é a de que sobrevivem ainda muitos elementos tomistas na sua obra. São geralmente atribuídos à importância que Hooker ${ }^{1}$ desempenhou na formação jurídico-política do grande empirista inglês. Mas quando se passa uma segunda vez pelos textos a sensação altera-se e aproxima-se daquilo que Haakonssen disse magistralmente: "Locke originally thought of natural law in traditional voluntarist-cum-realist terms" (HAAKONSSEN, 1996, p. 51). E é a fusão entre realismo e voluntarismo que pode provocar alguma perplexidade. Mas o realismo neste caso significa paradoxalmente artificialidade. Haakonssen toca o cerne do pensamento jurídico lockeano quando diz: "like Pufendorf, Locke argues, as part of his criticism of innate ideas, that moral phenomena are created by moral agents and imposed upon nature, which, in abstraction from such activity, is value-neutral" (p. 52).

Mas a verdade é que não é este o núcleo duro do pensamento de Locke. Verse-á mais à frente onde se situa o nó residual que compromete muito mais Locke com o nominalismo do que com o realismo. Darwall está já mais perto da verdade quando diz que Locke se situa no meio termo (Tal como Culverwell e Suarez) entre os (realist natural lawyers) teóricos realistas do direito natural que consideram que a lei natural moral existe e obriga intrinsecamente e os voluntaristas radicais que consideram que a obrigação depende inteiramente da vontade arbitrária de Deus (DARWALL, 1995, p. 24). Pessoalmente partilho esta ideia conquanto reconheça que Locke é muito

1 "The most famous and most influential of all modern natural right teachers was John Locke. (...) His authorithy seems to be Richard Hooker, (...) Now Hooker's conception of natural right is the Thomistic conception, in its turn, goes back to the Church Fathers, who, in their turn, were pupils of the Stoics, of the pupils of pupils of Socrates. we are then apparently confronted with an unbroken tradition of perfect respectability that streches from Socrates to Locke. But the moment we take the trouble to confront Locke's teaching as a whole with Hooker's teaching as a whole, we become aware that, in spite of a certain agreement between Locke and Hooker, Locke's conception of natural right is fundamentally different from Hooker's", in Strauss 1965: 165. De facto parece um paradoxo, mas não é. A corrente contínua que vai desde Socrates até Locke quebrou-se afinal. De facto já se tinha começado a quebrar com Hobbes, na opinião do autor, mas em minha opinião o começo deve atribuir-se a Grócio e até por maioria de razão. Mas é justo reconhecer que a ruptura com a tradição metafísica realista e intelectualista é muito maior com Hobbes do que com Grócio. Também não é menos verdade que a ligação estrutural entre o empirismo e o protestantismo, sobretudo influenciado pelo nominalismo, gerou muitas vezes uma consequência voluntarista que no plano jurídico se traduziu pela assunção de posições positivistas que empobrecem não só o próprio domínio jurídico, com a reflexão ético-moral que lhe anda associada, mas sobretudo porque tanto o voluntarismo quanto o positivismo reduzem a margem de manobra para o homem, sem a qual não se pode falar completamente em secularização e em autonomia. Enquanto existir a mínima persistência heterónoma no quadro de uma reflexão tanto moral quanto social e política, é ainda alguma coisa da velha armadura fundacionista teológicoMetafísica que se mantém, ainda que com outros alicerces ideológicos, não necessariamente melhores que os anteriores. $\mathrm{O}$ triunfo completo da secularização e da autonomia pressupõe a separação radical do domínio teológico, e portanto a superação completa de todos os elementos extrínsecos transcendentes ou transcendentais. 
convincentemente voluntarista quando o é e menos convincente quando cede ao realismo moral e jurídico.

A convicção que resulta da leitura de Locke é a mesma que Haakonssen exprime, quer dizer, a convicção de que o seu realismo é superficial e tem mais a ver com uma linguagem aprendida com Hooker e da qual Locke não teria tido a capacidade suficiente para se desfazer. Mas o que me parece mais importante é que Locke permite a sobrevivência de dois dispositivos completamente distintos. Eles seriam contraditórios se estivessem juntos, mas uma vez separados podem aceitar-se como momentos distintos da análise social ou mesmo como correspondendo a timings diferenciados. Neste plano a obra de Locke apresenta muitos pontos de proximidade estratégica com a obra de Pufendorf, que aliás reiteradamente elogiou, ou seja, a coabitação de posições voluntaristas com uma ideia de fundo racional e científica para a compreensão do fenômeno jurídico-político.

Por outro lado ainda, a dívida de Locke relativamente a Hobbes é explícita, tal como viu Leo Strauss ${ }^{2}$. O empiro-naturalismo de Locke é da mesma família epistêmica que o empiro-naturalismo hobbesiano, sendo que a posição de Hobbes é sempre menos ambígua e a separação entre o seu voluntarismo meramente teológico e a racionalidade da sua construção política é absolutamente nítida e evidente. Em Hobbes sente-se sempre que o voluntarismo teológico é coisa para Igreja ver e em boa verdade não tem nada a ver com o seu sistema de pensamento, racional, empírico e claramente laico e secularizado. São duas instâncias que quase não se tocam. Em Locke não é bem assim e o seu hiperaugustianismo, denunciado por Taylor, por Schneewind, por Haakonssen e por muitos outros, não deixa margem para dúvidas e contaminou explicitamente o seu pensamento ético-jurídico ${ }^{3}$.

\section{EXTERNALISMO E VOLUNTARISMO EM LOCKE}

$\mathrm{Eu}$, por mim, considero Locke um voluntarista e por via disso, quer dizer da posição extrínseca que toma relativamente ao fundamento da obrigação, um externalista. Desde o fundamento moral relativamente ao bem e ao mal que é definido a partir da questão do prazer e da dor até à ameaça consequente de rewards and punishments que se percebe que se realiza em Locke o clássico enlace entre o empirismo (sensista), o

2 "The period between Hooker and Locke had witnessed the emergence of modern natural science, of nonteleological natural science, and therewith the destruction of the basis of traditional natural right. The man who was the first to draw the consequences for natural right from this momentous change was Thomas Hobbes", in STRAUSS 1965: 165. E que influenciou, muito em particular, Locke, acrescentou Strauss.

3 "The Lockean (orthodox christianity) has Puritan roots, which means its background is in a hyperAugustinian theology". Exprime-se no homem uma espécie de "naturalistic transposition of the doctrine of original sin". Mas muito mais importante é o facto de que "he shares with the Puritans theological voluntarism. God's law is what he decides it is, and God's law determines the good", in TAYLOR 1989: 248. 
puritanismo (agostiniano) e o voluntarismo (positivista) e é claro que este dispositivo não contempla a autonomia humanista como objectivo central, nem podia contemplar, seja feita justiça ${ }^{4}$.

Mas o que perturba a tranquilidade do paradigma é que Locke, à semelhança de Hobbes, logra uma inesperada margem de manobra para a intervenção autônoma dos homens. E consegue mesmo numa área tão sensível quanto a área ético-moral e éticojurídica a assunção de uma posição internalista e autônoma. É como se o autor separasse radicalmente as duas esferas: a da fundamentação, que é externalista e mesmo transcendente e a da gestão dos recursos a partir de uma base pré-estabelecida. E essa é orientada pela razão, pelo poder da suspensão do juízo e da acção e pressupõe uma practical reasoning agency, no interior da qual todas as motivações, todos os cálculos e todos os processos são de natureza racional, prática e prudencial e em momento nenhum têm em conta senão aquilo que é o melhor para o agente na urdidura do seu bem e da sua felicidade. É como se o agente tomasse o freio nos dentes e a partir de um determinado momento não tivesse contas a dar a não ser a si mesmo. Então estaríamos na presença de um processo puramente secular e autónomo ${ }^{5}$. Darwall considera justamente por causa disso Locke um autonomista internalista de autodeterminação na linha de um neoplatônico como Cudworth ${ }^{6}$. Darwall abstrai-se do externalismo de fundo e do externalismo ao nível

4 Só em pensamentos menores, como é o caso do pensamento da maior parte dos autores portugueses do século XVIII, é que é possível encontrar combinados elementos ideológicos que são completamente contraditórios entre si e portanto incompatíveis.

5 Como se irá ver, essa autonomia é mais aparente do que real. Pode quando muito falar-se de uma semiautonomia e mesmo essa na perspectiva de que ocorre homologicamente, quer dizer num mundo duplicado. Por um lado os homens exercem autonomamente a capacidade de reflectir sobre aquilo que lhes interessa, mas isso ocorre no seio de uma crença mais abrangente, de que estamos sob as leis de Deus e de que lhes devemos obediência. Porque em última análise a lei de Deus é "the only touchstone of moral rectitude", in Locke 1995: 280 [1690]. Ou como Locke disse logo na introdução: "Hence naturally flows the great variety of opinions concerning moral rules which are to be found amongst men, according to the different sorts of happiness they have a prospect of, or propose to themselves; which could not be if practical principles were innate, and imprinted in our minds immediately by the hand of God. I grant the existence of God is so many ways manifest, and the obedience we owe him so congruous to the light of reason, that a great part of mankind give testimony to the law of nature; but yet I think it must be allowed that several moral rules may receive from mankind a very general approbation, without either knowing or admitting the true ground of morality; which can only be the will and law of a God, who sees men in the dark, has in his hand rewards and punishments, and power enough to call to account the proudest offender", in LOCKE 1995: 29 [1690].

6 Mesmo assim Darwall cuida-se de não exorbitar na terminologia, uma vez que guarda para autores como Shaftesbury, por exemplo, a dimensão da autorregulação e do autogoverno. Ora, só há autonomia completa se o agente tiver dentro de si não apenas os instrumentos para se auto-determinar em função de premissas e pressupostos que já o enformam, mas se, muito mais radicalmente, for ele o depositário de todos os intrumentos de ponderação e decisão. Para Locke, a moralidade obriga-nos porque é prescrita com autoridade, a partir de um ser superior, exterior ao eu. (...) Mas muito mais claramente que em Locke ou Cudworth, autores como, Shaftesbury conceberam a autodeterminação como auto-regulação e auto-governo. E Shaftesbury limita-se a inaugurar uma tradição que culminará no intuicionismo moral da razão ou do senso que já analisámos detalhadamente. (...) Em Shaftesbury o governo moral é auto-governo. A autoridade existe mas permanece no interior do agente. Assim ele 
da obrigação para valorizar essencialmente o plano da motivação e ainda mais o plano da decisão racional prática.

\section{A PRESENÇA DE EPICURO NA PROPEDÊUTICA MORAL DE LOCKE. PRAZER E FELICIDADE}

O ponto de partida no pensamento de Locke é, tal como em Hobbes, a problemática do bem e do mal, por um lado, do prazer e da dor, por outro lado. Mas o que estabelece o nexo entre as duas instâncias são dois conceitos absolutamente nucleares: happiness e uneasiness (felicidade e desconforto ou insatisfação).

Antes de passar para o ponto que articula os vários planos do problema interessa deixar já bem claro que a posição de Locke é epicurista no plano da fundamentação do problema do bem e do mal e sensista no plano gnoseológico em convergência, de resto, com o seu epicurismo de base. Quer isto dizer que os homens recebem através da sensação, e só da reflexão depois, as ideias de prazer e de dor, que são estas ideias que determinam as ideias de bem e de mal, o que significa, desde logo que o homem não as possui nem possui nenhum órgão intelectual ou sensível capaz de as criar ou produzir ou captar directamente a partir de essências à margem da experiência sensitiva em contacto com o mundo: "Things then are good or evil only in reference to pleasure and pain. That we call 'good', which is apt to cause or increase pleasure, or diminish pain, in us; or else to procure or preserve us the possession of any other good, or absence of any evil. And, on the contrary, we name that 'evil', which is apt to produce or increase any pain, or diminish any pleasure, in us; or else to procure us any evil, or deprive us of any good" (LOCKE, 1995, p. 160 [1690]).

A posição não difere muito da posição de Hobbes. Em boa verdade não difere nada se se tiver em conta que imediatamente a seguir Locke tratará de dizer que as paixões que são movidas pelo bem e pelo mal, são de facto movidas pelo prazer e pela dor. Se se identificarem as paixões em Locke com o desejo em Hobbes, chega-se à conclusão que a fórmula é a mesma, isto é o homem chama bem àquilo que deseja e

interioriza a normatividade ao interiorizar a autoridade. Fundamental: Só se o agente observa as suas melhores auto-prescrições como sendo autoritárias e obrigatórias, e actua de acordo com elas, a actividade auto-determinada é possível. Autodeterminação, para se conformar com as exigências da autonomia, requer auto-governo. E este requer que o agente seja predominantemente movido, e a sua conduta determinada, por uma concepção normativa que ele aceita. Pode-se chamar a isto uma normativa teoria da vontade, cf. DARWALL 1995: 205, 206.

É neste ponto que Shaftesbury mais se aproxima de Kant uma vez que esta vontade racional de Shaftesbury permite defender a ideia já kantiana de que a moralidade obriga porque uma vontade racional livre age debaixo de uma ideia de lei que no entanto o agente ele próprio produziu. Ele é lei para si mesmo. Tudo o que tenho tentado dizer no sentido de que se perceba a minha ideia de autonomia está muito bem resumida nesta última proposição: no quadro da autonomia o agente produz a lei e depois torna-se a lei para si mesmo, porque se submete à lei que ele próprio produziu. Por isso venho considerando o pacto como o instrumento social que exprime na realidade a natureza teorética da autonomia. 
chama mal àquilo de que sente aversão, porque é óbvio que deseja o bem e sente aversão pelo mal, mas sempre em última instância porque identifica o bem com o prazer e o mal com a dor. E de resto, no amplo campo das paixões inventariado por Locke, logo se percebe que é o desejo que é responsável pela uneasiness, quer dizer pelo sentimento de insatisfação e desconforto. Ora, é a insatisfação do desejo que determina a vontade, sendo que é o bem, o maior bem, que determina justamente essa insatisfação.

Portanto e por ordem: É a existência de qualquer coisa como o maior bem que estimula um sentimento de insatisfação e desejo ${ }^{7}$, este sentimento mobiliza a vontade e a vontade põe em marcha os mecanismos tendentes à obtenção desse maior bem. Só então entra a razão, prática e auxiliar, para procurar os melhores caminhos e evitar os maus. Ora, só falta designar esse greatest good pelo seu termo adequado, felicidade ${ }^{8}$.

Vamos assim começar pela felicidade uma vez que é a sede de felicidade que estimula a autoconsciência da insatisfação:

"All desire Happiness. - If it be farther asked, what it is moves desire? I answer, Happiness, and that alone. "Happiness» and «misery» are the names of two extremes, the utmost bounds whereof we know not: it is what «eye hath not seen, ear hath not heard, nor hath it entered into the heart of man to conceive». But of some degrees of both we have very lively impressions, made by several instances of delight and joy on the one side, and torment and sorrow on the other; which, for shortness'sake, I shall comprehend under the names of «pleasure» and «pain», (...) Happiness, what. - (...) for no other reason but for its aptness to produce pleasure and pain in us, wherein consists our happiness and misery" .

Até aqui Locke não acrescenta nada de muito especial àquilo que foram ao longo da História das Ideias as posições hedonistas, subordinadas à persistência de uma equação que articula, prazer, dor e felicidade. Salvo, talvez o conceito de uneasiness, mas só pela

7 O princípio remoto da insatisfação é, ele próprio, agostiniano. Para Santo Agostinho foi Deus que colocou no coração dos homens este desejo infinito e insaciável, motivo e razão para a procura e para o aperfeiçoamento moral e religioso. A insatisfação estimula a procura de todos os meios legítimos para a satisfação. Na perspectiva agostiniana a insatisfação provoca um vazio ontológico que exige um aprofundamento ontológico e uma expansão do ser que assim realiza a vocação metafísica da existência.

8 "By «reason", however, I do not think we should understand here that faculty of the intelect, (...) but some definite practical principles from which flow the sources of all virtues (...) What is rightly deduced from these principles is properly said to conform to right reason", cf. John Locke [Questions concerning the law of nature], in HORWITZ 1990: 99.

9 Que esta é uma posição inabalável de Locke prova-o o número de vezes em que na sua obra o afirma categoricamente. Devo trazer aqui um texto (um fragmento) intitulado “Thus I think", citado por Lord William King, na obra "Life of Locke", segundo vol., p. 120, em que se atribuem a Locke as seguintes palavras: "It's a man proper business to seek happiness and avoid misery". E onde a procura da felicidade aparece reforçada com o sentido de que esse objectivo é a condição própria do homem. Mantém-se aqui muito do entendimento clássico sobre o assunto mas também medieval, ainda que o conceito possa estar travestido de beatitude. Desde Aristóteles até S. Tomás de Aquino passando pelo Santo Agostinho dos tempos de Cassicíaco, que a felicidade é entendida como a finalidade por excelência do homem. Esse teleologismo está em Locke, pelo menos neste fragmento. 


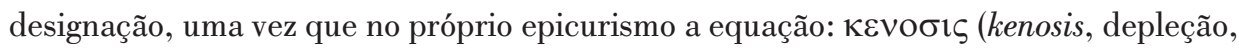
esvaziamento) - $\varepsilon v \delta \varepsilon 1 \alpha$ (endeia, falta, necessidade), $\varepsilon \pi 1 \vartheta \cup \mu 1 \alpha$ (epithymia, desejo) e $\alpha \nu \alpha \pi \lambda \eta \rho \circ \sigma ı$ (anaplerosis, enchimento, satisfação), contém o momento da uneasiness na figura semântica da $\varepsilon v \delta \varepsilon 1 \alpha$ (endeia). Esta equação, mau grado a longa tradição de calúnias antiepicuristas, é muito mais cirenaica do que epicurista. É que o objetivo epicurista consiste ou consistiu sempre em pôr termo a este processo infernal. Segundo esse objetivo, no epicurismo foi sempre ou é sempre proposto como termo final da equação, não um elemento conjuntural e provisório, mas se possível definitivo, e que é a katastematike $(\chi \alpha \tau \alpha \sigma \tau \eta \mu \alpha \tau \imath \chi \eta ́)$, ou seja, a serenidade de um estado estável donde se ausenta toda a pertubação. Este estado estável deve ser portanto dominado pela tranquilidade, o que só pode ocorrer no quadro de um prazer estático (permanente), onde pelo equilíbrio e pela ausência de esvaziamento se interrompe o ciclo infernal e sempre repetido. É por isso que o conceito de ataraxia $(\alpha \tau \alpha \rho \alpha \xi i ́ \alpha)$ é determinante e decisivo. Só em estado de ausência de perturbação e em plena tranquilidade pode o sábio encontrar a felicidade. $\mathrm{O}$ que eu quero dizer é que esta equação é cirenaica e se ocorre no epicurismo, só ocorre porque alguma coisa falhou, uma vez que o sábio epicurista jamais abandona o estado de tranquilidade e de ataraxia para correr atrás de prazeres condenados ao malogro. O malogro é justamente esta insatisfação, acompanhada infinitamente das etapas subsequentes numa lógica infernal sem fim. O processo pode ser travado tanto na lógica epicurista como na lógica estóica pela introdução do elemento da apatia nos estóicos e da ataraxia nos epicuristas e a atitude de espírito que funciona

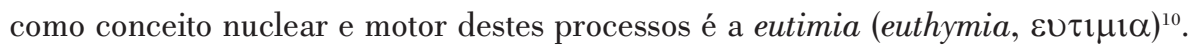

Pela leitura que faço, no plano do seu hedonismo, depreende-se que Locke é mais cirenaico que epicurista, embora tudo leve a crer ele tenha entrado em contacto em França com o universo ideológico do círculo neoepicurista. Mas também se sabe que até em França a lógica neoepicurista conduziu não a um epicurismo suave à imagem e semelhança do modo de vida do sábio do jardim, mas em alguns casos à perspectiva de um libertinismo deletério.

\section{LOCKE: PRUDÊNCIA E $<<$ SUSPENSÃO $>>$}

Ora, a novidade está na combinação de dois elementos distintos da cultura antiga. Locke revisita ao mesmo tempo o hedonismo antigo com um vago sabor epicurista e ao mesmo tempo o cepticismo, uma vez que propõe uma espécie de epoché, com a particularidade de que esta epoché seja essencialmente prática e portanto mais ligada à

10 "Euthymia suggests Democrito, allows man the opportunity to be content and unruffled in the face of misfortune. It provides «imperturbable wisdom», to face life's adversities and suffer as little as possible from the disturbances which threaten the equanimity of other men", in HIBLER 1984: 27. 
vida moral que à vida epistémica, e por isso também mais da ordem da razão prática e não da razão teorética. Mas seja como for a figura da suspensão terá sempre um sabor relacionado com o pirronismo. E é esta, a meu ver, a grande originalidade de Locke, aquela que lhe permite uma certa distanciação relativamente ao voluntarismo da sua base moral e ético-jurídica. Só um sabor porque agora a suspensão do desejo, do juízo e da acção está amplamente subordinada à convicção intelectual de que a procura de felicidade exige esta espécie de jurisprudência.

De fato a expressão da jurisprudência não é inocente, porque eu quero com ela reaproximar-me outra vez de Epicuro, agora sim com convicção. É que também em Epicuro estava subentendido este papel prudencial da razão, e este poder de suspensão outra coisa não é do que um poder prudencial. Em Epicuro ele estava atribuído à phronesis, virtude cardeal e iluminante do caminho a seguir, que nas Máximas vaticanas, o Sábio convoca apropriadamente: "La fortune a peu de prise sur le sage, car, les choses les plus grandes et les plus importantes, la raison calculante les a réglées, et, pendant toute la durée de la vie, les régle et les règlera" (EPICURO COUCHE, In: CONCHE, 1992, p. 237). E na Carta a Meneceu não se coibe de identificar como o maior bem, sobretudo quanto ao facto de que o agente deve escolher acertadamente sobre os caminhos a seguir em ordem a encontrar o caminho para a felicidade, ou seja, o caminho para a vida boa: "Quand donc nous dison que le plaisir est la fin, nous ne parlons pas des plaisirs des gens dissolus (...) mais le raisonnement sobre cherchant les causes de tout choix et de tout refus, et chassant les opinions par lesquelles le trouble le plus grade s'empare des âmes. (...) Le principe de tout cela et le plus grand bien est la prudence (

A convicção que tenho do contacto de Locke com o pensamento epicurista e o fato de, desde a ética a Eudemo de Aristóteles, a phronesis ter evoluído no sentido de uma sabedoria com maior acuidade prática, no sentido portanto de uma pudência, tudo isso me leva a pensar que é num sentido puramente prudencial que a fórmula da suspensão deve ser entendida e não na perspectiva de uma tranquilidade teorética. A suspensão é assim mais suspensão do desejo e da ação e menos suspensão do juízo.

Mas anote-se então, em concreto, que direcção tomou a prudência em Locke, já que é de prudência que se está a falar:

"The Power to suspend the Prosecution of any Desire makes way for Consideration. There being in us a great many uneasinesses, always soliciting and ready to determine the will, it is natural, as I have said, that the greatest and most pressing should determine the will to the next action; and so it does for the most part, but not always. For, the mind having in most cases, as is evident in experience, a power to suspend the execution and satisfaction of any of

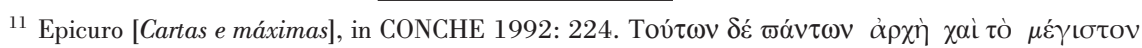

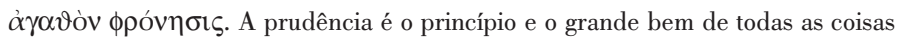


its desires, and so all, one after another, is at liberty to consider the objects of them, examine them on all sides, and weigh them with others. In this lies the liberty man has; and from the not using of it right comes all that variety of mistakes, errors, and faults which we run into in the conduct of our lives, and our endeavours after happiness, whilst we precipitate the determination of our wills, and engage too soon, before due examination. To prevent this, we have a power to suspend the prosecution of this or that desire, as everyone daily may experiment in himself. This seems to me the source of all liberty; in this seems to consist that which is (as I think improperly) called free-will. For, during this suspension of any desire, before the will be determined to action, and he action (which follows that determination) done, we have opportunity to examine, view, and judge of the good or evil of what we are going to do; and when, upon due examination, we have judged, we have done our duty, all that we can, or ought to do, in pursuit of our happiness; and it is not a fault, but a perfection of our nature, to desire, will, and act according to the last result of a fair examination (...) The Reason of it. This is the hinge on which turns the liberty of intellectual beings, in their constant endeavours after, and a steady prosecution of, true felicity, that they can suspend this prosecution in particular cases, till they have looked before them, and informed themselves whether that particular thing which is then proposed or desired lie in the way to their main end, and make a real part of that which is their greatest good" (LOCKE, 1995, p. 184-187 [1690]).

Ora, e isto é decisivo no pensamento de Locke, a verdade é que a obrigação de suspender os desejos é um imperativo determinado pela obrigatoriedade moral que o homem tem de se bater pela sua felicidade, isto é, de procurar aquilo que lhe traz prazer e combater aquilo que lhe traz dor, pois é assim que simultaneamente se bate pelo bem contra o mal. Nesse contexto o reino da necessidade tem que ser abolido. Não faz sentido para Locke, uma vez que isso seria contranatura, crer num determinismo de tipo metafísico que conduziria à felicidade. Isso pressuporia duas coisas, ambas erradas para Locke: uma, a clarividência que resultaria da existência de princípios orientadores inatos em nós. Outra, uma perfeição metafísica, personalizada na perfeição das nossa faculdades. Ora, se o puritanismo moral de Locke impede a segunda possibilidade, o empirismo anti-inatista impede a primeira e a relação de contraposição que ambas expressam relativamente ao nominalismo occamista, tão do agrado de Locke, impede as duas simultaneamente. O que há de especificamente humano é a sua liberdade. A liberdade não coroa uma ideia de perfeição, consagra, pelo contrário, uma ideia de deficiência. Deus, na sua perfeição, não precisa da liberdade nem do livre-arbítrio, e muito menos de suspender o seu desejo ou as sua ações e muito menos ainda, por maioria de razão, os seus juízos. A sua omnisciência e a sua perfeição colocam-no imediatamente no caminho certo.

A liberdade é uma consequência da imperfeição humana que necessita para a sua realização de utilizar o mecanismo da suspensão do desejo: “ce qu'il y a de spécifiquement humain dans la liberté à la Locke, c’est, par conséquent, une rupture avec les désirs particuliers, qui sont naturels et présents, donc une rupture avec la nature temporelle et sensible, grâce au contact pris dans un jugement droit, avec le vrai bonheur de l'homme et avec son essence réelle, avec sa nature parfaite, dans la mesure où celle- 
ci relève de l'éternel" (POLIN, 1960, p. 22). O raciocínio de Raymond Polin coloca Locke no caminho de Santo Agostinho e isso deveria agradar-me, uma vez que o seu raciocínio vai no mesmo sentido que o meu, mas a verdade é que não me posso solidarizar com esta ideia de que existiria em Locke um juízo direito que colocaria, segundo o seu ponto de vista, o homem na direção de uma felicidade entrevista a priori, como corolário da essência real da felicidade e do homem.

\section{RAZÃO PRÁTICA: $<<$ PRACTICAL AGENGY $>>$.}

O internalismo autonomista de que fala Stephen Darwall coloca Locke dentro de um relativismo moral centrado nas motivações e numa decisão moral sempre prática e sempre aberta. Não há nada que corresponda a uma decisão global, a priori, mas há antes, e pelo contrário, uma practical agency permanentemente centrada no exercício reiterado da suspensão e da prudência. É nisso que consiste a autonomia possível do agente. É verdade que suspende os desejos particulares para poder optar com sabedoria, mas o agente não o faz no pressuposto de que pode encaminhar-se para uma espécie de absoluto. $\mathrm{O}$ agente interrompe a prossecução de desejos particulares mas opta sempre pela prossecução de objectivos conjunturais e contingentes. É claro que o agente possui a ideia de uma finalidade, até porque se não possuísse ideia nenhuma ficaria obviamente paralisado. De facto, o agente possui sempre qualquer coisa que possa funcionar como motivo para desencadear o processo do desejo, simplesmente o caminho está sempre em aberto.

Mas a verdade é que se na aparência Locke insititui um reino de absoluta liberdade e desse modo se colocaria no enquadramento de uma perspectiva que abriria caminho, disso estou certo, ao advento de uma autonomia genuinamente humanista, é a própria base de sustentação da sua argumentação que, cedendo aos lugares comuns da tradição escolástica, trai os desígnios do autor e abre paradoxalmente caminho a uma interpretação metafísica, e, especificamente, do determinismo metafísico tomista. Sobretudo quando afirma:

"For the inclination and tendency of their nature to happiness is an obligation and motive to them, to take care not to mistake or miss it; and so necessarily puts them upon caution, deliberation, and wariness, in the direction of their particular actions, which are the means to obtain it. Whatever necessity determines to the pursuit of real bliss, the same necessity, with the same force, establishes suspense deliberation, and scrutiny of each successive desire, whether the satisfaction of it does not interfere with our true happiness, and mislead us from it. This, as seems to me, is the great privilege of finite intellectual beings" (LOCKE, 1995, p. 187 [1690]).

Inclinação e tendência para, que é no seu pensamento uma necessidade várias vezes assumida, conferem ao pensamento de Locke uma conotação finalista e teleológica, 
que não se encontra por exemplo em Hobbes. Em Hobbes há uma pulsão absolutamente naturalista e biológica, que se prende com o estado de natureza, e que é o instinto de sobrevivência ou de preservação. Nada que se pareça com esta tendência e inclinação para a realização da natureza do homem e da sua perfeição. Chame-se-lhe felicidade ou não. A obrigatoriedade do homem à felicidade é do reino da necessidade e para que ele não a falhe ela é acompanhada de uma obrigação moral.

E de fato, pelo menos uma vez na sua obra, Locke estabelece um nexo real e concreto entre a realização da natureza humana como realização da sua perfeição e a realização da sua felicidade: "As therefore the highest perfection of intellectual nature lies in a careful and constant pursuit of true and solid happiness" (p. 187). E só depois enfatiza a articulação com a liberdade: "so the care of ourselves, that we mistake not imaginary for real happiness, is the necessary foundation of our liberty" (p. 187). E a prova de que a realização da felicidade é a realização da perfeição da natureza humana ou, em última instância, aquilo para que fomos criados é que Locke não se lamenta das deficiências e da imperfeição constitutiva dos homens. O que ele diz é mais ou menos o seguinte: se formos humildes e modestos não nos sentiremos frustrados e nem podemos deitar as culpas das nossas imperfeições para cima de Deus, uma vez que ele nos forneceu as faculdades suficientes para lograrmos realizar a nossa natureza e os nossos objectivos terrenos. A nossa capacidade está no fim de contas adequada aos nossos objectíveis possíveis.

"For though the comprehension of our understanding comes exceeding short of the vast extent of things, yet we shall have cause enough to magnify the bountiful Author of our being for that portion and degree of knowledge he has bestowed on us, (...) We shall not have much reason to complain of the narrowness of our minds, if we will but employ them about what may be of use to us (...) Men have reason to be well satisfied with what God hath thought fit for them, since he has given them, as S. Peter says: «Whatsoever is necessary for the conveniences of life, and information of virtue», and has put within the reach of their discovery the comfortable provision for this life, and the way that leads to a better" (p. 3). [tudo pela vida e pelo amor (da virtude)]

Porque a tarefa do homem na terra não é a de conhecer tudo mas apenas conhecer e usar aqueles saberes que dizem respeito à sua conduta, ao seu comportamento acertado, a fim de que possa lograr o grande objetivo humano possível, ou seja, a felicidade. Portanto a natureza humana concebida por Deus é perfeita, a seu modo. Por exemplo a uneasiness não é um elemento negativo, mas, pelo contrário, desempenha um papel motor mediante o qual o homem se põe em marcha. $\mathrm{O}$ sofrimento de falta, a inquietação que resulta da insatisfação que essa falta provoca, estimula a procura. As paixões são positivas, desde que usadas, como se verá, com moderação. A uneasiness é decisiva. Até parece que Deus terá tido isso em conta, uma vez que é a incompletude que mobiliza a ação e com ela se mobilizam as qualidades próprias do homem, à cabeça das quais é legítimo colocar a liberdade. À semelhança de Santo Agostinho que coloca a incompletude 
ontológica como fonte do desejo, desejo que ao visar à beatitude visa ao bem e escolhe o caminho apropriado, no seu caso pela mobilização das virtudes, para o atingir, também aqui a uneasiness estimula o desejo, a procura e o caminho para a realização do objetivo, sendo que, tal como nas tradições eudemonistas, a felicidade é o bem supremo e a sua realização é a realização da perfeição.

Em Locke, porém, há a assunção de que não se visa à divindade, mas apenas à perfeição menor de um ser imperfeito. E agora, circularmente, é justamente porque é imperfeito e deficiente que precisa da liberdade de suspender os seus desejos para não se precipitar e assim cair no erro; erro esse, que é o mau caminho, ou seja aquele que conduziria não ao highest good, ou seja, à felicidade, mas antes à miséria. E por que é que a miséria é miséria e a felicidade é o bem? Muito simplesmente porque o prêmio da miséria é a dor e o prêmio da felicidade é o prazer. O princípio da suspensão desempenha assim no plano prático e terreno o que o princípio da Graça desempenha no plano transcendente. Ambos assistem à criatura imperfeita e deficiente. Esta lógica da imperfeição e da deficiência faz corpo com o hiper-augustinianis- mo de Locke e resulta da sua formação puritana. Mais uma vez a combinação do empirismo com o sensismo do prazer e da dor faz corpo com uma antropologia pessimista e sombria. Tanto mais que, em simultâneo, se assiste a uma colocação da fasquia baixa no que diz respeito às faculdades racionais e intelectuais do homem. Estas faculdades, reduzidas em Locke à prossecução de soluções práticas, perderam seguramente o élan que apresentavam por exemplo no humanismo do Renascimento e no neoplatonismo de Cambridge.

\section{APESAR DE TUDO UM INTELECTUALISMO RESISTENTE}

Agora o que é de fato paradoxal é a emergência de uma redefinição da teoria neoclássica do argumento ontognoseológico ${ }^{12}$ com o consequente enfeudamento moral às noções nada voluntaristas da medida, do limite, da moderação etc. Locke começa por acentuar que a mãe de todos os erros é a nossa ignorância logo seguida da nossa inadvertência. Se a referência à ignorância coloca Locke mais perto da tradição intelectualista, a inadvertência ainda mais, uma vez que esse argumento foi reiteradamente utilizado, por exemplo, por Cícero e por S. Tomás de Aquino. Em S. Tomás o recurso à inadvertência, não no sentido da animadversão, mas no sentido de uma presunção, de uma leviandade, de um convencimento narcísico, que é genuinamente humanista segundo as teologias mais integristas, é mesmo o fundamento por excelência do mal.

12 "It is impossible anyone should willingly put into his own draught any bitter ingredient, or leave out anything in his power that would tend to his satisfaction and the completing of his happiness, but only by wrong judgment", in LOCKE 1995: 193 [1690]. É o juízo errado, a ignorância portanto que conduz ao erro, ao erro moral, porque é uma imoralidade errar na prossecução da felicidade. Isso também é uma das facetas do mal. 
Uma vez que o mal não tem essência ${ }^{13}$, ele está apenas no erro da escolha, e uma vez que o intelectualismo tomista o impede de conceber uma vontade obstinadamente má já que segundo o argumento ontognoseológico só se pratica o mal porque se erra, e erra-se por ignorância, S. Tomás encontrou este meio termo entre o mal-erro e o malvontade-má nesta escolha que não é deliberadamente má, o que conferiria essencialidade ao $\mathrm{mal}^{14}$, mas também não é sinal de pura ignorância, o que laicizaria em excesso o seu pensamento teológico ${ }^{15}$, no fim de contas, mediante o recurso a esta escapatória da inadvertância, da leviandade. A lógica da inadvertência, na perspectiva de uma leviandade responsabilizável, está bem sintetizada na expressão de que o agente atua sem ter a regra em conta, como se não precisasse dela. Regra que em latim se diz regula e que de algum modo conecta com régua e que de uma forma metaforicamente mais clara quer dizer que aquele que não tem em conta a regula denuncia a arrogância e o orgulho de quem se tem como regra e régua para si mesmo. De algum modo sabe-se por experiência própria que é difícil a linha reta sem a régua e, ainda que metaforicamente, tudo isto remete para a ideia de que a retidão sem a régua, quer dizer sem a regra é obra tão difícil, que provavelmente só pode ser obra de Deus ${ }^{16}$.

13 “Quod malum non est aliqua natura” (O mal não é uma natureza). O mal (dado que é uma privação), não é nunca causado de forma directa. O mal é sempre um efeito secundário, causado indirectamente. E o mal moral é um caso particular disso. Sendo assim pode-se se dizer que o mal provem de uma vontade que escolhe um fim ilegítimo (Finis indebitus).

${ }^{14}$ A essencialidade do mal seria uma aberração uma vez que a escolástica escolheu o princípio da convertibilidade do bem (ens et bonum convertuntur = aquilo que é, enquanto tal, é bom), cujos fundamentos se encontram na filosofia socrático-platónica. Por outro lado em Aristóteles o bem é aquilo que todas as coisas desejam (Hinc est quod philosophi diffinientes bonum dixerunt: bonum est quod omnia appetunt, Arist., E. N., I, 1) o que não afronta a teoria anterior na medida em que a natureza em Aristóteles não é definida em termos estáticos mas dinâmicos, quer dizer em termos teleológicos. Dizer que o bem é o que todas as coisas desejam é dizer que ele é a natureza de todas as coisas, porque a natureza das coisas é aquilo para que tendem, logo ele é o ser, tal como no pensamento socrático-platónico.

${ }^{15}$ S. Tomás não podia, por outro lado, ter sido completamente indiferente a uma outra tradição da escolástica que mergulhando as suas raízes em Santo Anselmo, mostrava já sinais de revitalização através das obras de Alexandre de Halles, Jean de La Rochelle e S. Boaventura entre outros. Estou, bem entendido, a falar da escolástica franciscana, que culminará, em época um pouco posterior à de S. Tomás, nas obras de Duns Scoto e Guilherme de Ockham.

${ }^{16}$ São várias as formulações aquinianas que exprimem este ponto de vista. $\mathrm{O}$ mal está fora da intenção. Defeito de consideração (De ter em consideração). Falta de ordenamento (de o acto ser levado a cabo segundo a ordem). Acção que a vontade poderia ter evitado. Ausência de querer. Nunca o resultado de um querer, de uma vontade de transgressão. Eu teria e deveria ter podido considerar, mas não o fiz. Assim não ter tido em conta. Não atenção à regra. Aliás S. Tomás enfatiza de uma forma absolutamente original o papel da regulação, de adesão a uma regra. Mas na raiz do desregramento está sempre um defeito de atenção. Uma ausência da atenção devida a Deus. E isso acaba por conduzir ao orgulho, no sentido de uma procura do bem próprio sem a consideração do que deveria regular essa procura. Cf. AQUINO, Suma C. G. III, 10; III, 109.

E finalmente o que se subentende na crítica e na condenação dessa não consideração ilumina bem o que S. Paulo diz: "puisque connaisant Dieu, ils ne l'ont ni glorifié ni remercié comme Dieu; au contraire ils sont devenus 
Mas é verdade que o precursor desta inadvertência no sentido de uma animadversão - e é sempre animadversão, ainda quando é inconsciente e involuntária a inadvertência é animadversão na prática - foi Cícero. No De Officis, I, 103 Cícero diz: "exercitandam esse animadversionem et diligentiam, ut ne quid temere ac fortuito, inconsiderate negligenterque agamus", que corresponde, traduzindo essencialmente o sentido, mais ou menos, à ideia de que não se deve fazer nada de modo ligeiro e ao acaso, ou seja, de maneira irrefletida e negligente.

Em Locke, de novo, a inadvertência tem o significado que, no fim de contas, lhe conferem tanto Cícero quanto S. Tomás, ou seja: "When a man overlooks even that which he does know. This is an affected and present ignorance, which misleads our judgments" (LOCKE, 1995, p. 195 [1690]). A inadvertência tem para Locke uma gravidade maior do que a ignorância porque acaba por ter a mesma consequência e funcionar como se de uma completa ignorância se tratasse. É uma leviandade, uma irresponsabilidade diria eu na nossa linguagem contemporânea. E portanto a inadvertência é, do ponto de vista moral, muito mais grave que a ignorância. Aliás, a ignorância só é imputável moralmente se ela obedece ao mecanismo psicológico da inadvertência, quer dizer se o agente poderia não dar conta de uma ignorância acaso fosse mais preocupado, ou seja, mais responsável. Overlook significa mesmo não ter em devida conta.

Depois Locke entra no domínio das paixões desreguladas, cedendo claramente aos contornos de uma propedêutica antropológica coerente com a sua formação religiosa. Locke refere-se muitas vezes à fragilidade ôntica das criaturas e à sua imperfeição, ou no fim de contas à natureza corrupta do ser pós-lapsário, na linha, aliás, dos seus mestres, como é o caso de S. Paulo que cita a propósito do célebre: "Car ce que je fais, je ne le comprends pas; car ce que je veux, je ne le pratique pas, mais ce que je hais, je le fais, (...) car le bien que je veux, je ne le fais pas, mais le mal que je ne veux pas, je le pratique"17. Mas também na linha de Santo Agostinho e dos teóricos do protestantismo e do puritanismo, sobretudo Calvino. É verdade que traz o assunto para a terra, mas o significado é o mesmo ${ }^{18}$. E a primeira solução que ocorre a Locke no quadro daquilo que posso considerar a sua posição terrena, humanista e promotora de uma certa margem de autonomia, autonomia incompleta como se irá ver, é a identificação de um modo de vida em que as paixões desregradas devem ser trazidas à ordem, ou seja à medida. Locke chega mesmo a falar de mediocridade como sendo o ideal de vida, uma vida

\footnotetext{
vains dans leurs raisonnements" (Rom. I, 21). E é sempre aqui que vamos desembocar: ao crime de orgulho, ao humanismo. Aos raciocínios vãos.

${ }^{17}$ ROM. 7, 15 e 19.

18 “(...) that though all men desire happiness, yet their wills carry them so contrarily, and consequentley some of them to what is evil", in LOCKE 1995: 188 [1690].
} 
mediana portanto, apolínea no fim de contas. Como numa carta ao Conde de Pembroke. "I have often thought that our state here in this world is a state of mediocrity, which is not capable of extremes" (POLIN, 1960, p. 43).

Mas o seu sentido da moderação ${ }^{19}$, da proporção e da medida é seguramente o resultado da sua outra formação estóico-epicurista, quer dizer, de uma formação obtida através, sobretudo, do contacto com o caldo ecléctico do academismo e do medioplatonismo, isto é: Cícero, Plutarco e Séneca, sobretudo. Polin sintetiza bem o ideário moral e existencial de Locke: “En définissant l'homme par sa fonction obligée en vue de sa fin, le bonheur raisonnable, Locke a préféré à une définition de l'homme par sa nature et par ses faits, une définition morale et il a subordonné son anthropologie à une morale de la mesure du sens des limites et des compromis raisonnables" (POLIN, 1960, p. 45).

Já disse que intuo uma autonomia mais aparente do que real, embora eventualmente possante no plano do practical reasonning, ou, se se preferir, no sentido de uma practical agency. Interessa percorrer os textos onde Locke mais evidencia o sentido da autonomia, nomeadamente o Livro I e o Livro IV do Ensaio sobre o entendimento humano e a Carta sobre a tolerância. O resultado é decepcionante. Locke explora sobretudo a autonomia relativamente aos outros, estimulando cada homem a deixar-se guiar pelo seu próprio juízo, pondo obviamente termo aos ídolos, às ideias feitas etc., e de resto tudo isso em articulação, mormente, com a dimensão exclusivamente prática da ação, quer dizer no sentido do reforço da capacidade raciocinante implícita na suspensão dos desejos, uma vez que essa suspensão é intencionalmente a abertura de um tempo de ponderação, de cálculo, de reasonning, enfim. E finalmente tudo isso ocorre no contexto de um reforço do culto de uma racionalidade anti-inatista. E pouco mais do que isso.

\section{TRIUNFO FINAL DA LÓGICA REPRESSIVA E HETERÔNOMA}

Mantenho que no mesmo capítulo em que sobre o poder se explicitam e promovem os poderes próprios do homem, se faz também o diagnóstico das suas limitações profundas e assim se lançam os caboucos de uma filosofia que lança as bases da morte da autonomia. Uma morte anunciada. Anunciada porque em minha opinião ela estava já subentendida na definição do bem e do mal a partir do prazer e da dor. E a verdade é que aí está agora finalmente a articulação completa, assim como a enumeração de todas as partes do sistema:

19 De todo o modo não se pode esquecer que Locke só tem em conta o dispositivo da moderação e repressão das paixões nas circunstâncias definidas no § 53, do cap. XXI do Livro II: Quando "any extreme disturbance (as sometimes it happens) possesses our whole mind, (...) allows us not the liberty of thought, and we are not masters enough of our minds to consider thoroughly and examine fairly", In: LOCKE 1995: 188 [1690]. 
"Good and evil, as hath been shown (book ii, cha. xx, sect. 2, and chap. xxi, sect. 42), are nothing but pleasure or pain, or that which occasions or procures pleasure or pain to us. Moral good and evil, then, is only the conformity or disagreement of our volontary actions to some law, whereby goof and evil is drawn on us from the will and power of the lawmaker; which good and evil, pleasure or pain, attending our observance or breach of the law, by the decree of the law-maker, is that we call «reward» and «punishment»" (p. 279).

E o sentido encontra-se no fato de que o que os rewards and punishments prometem é justamente prazer e dor. $\mathrm{O}$ enlace está assim feito entre a dimensão imanente, terrena, da procura da felicidade e a lógica transcendente, uma vez que em última análise a lei é a lei de Deus ${ }^{20}$, e os castigos e remunerações são divinos também. Tudo o resto é o resultado de uma homologia.

Existe liberdade nessa realidade homóloga, liberdade e autonomia, mas obviamente relativa. Já no $§$ anterior Locke chama a atenção para o fato de que uma relação moral outra coisa não é senão “the conformity or disagreement (that) men's voluntary actions have to a rule to which they are referred, and by which they are judged of” (LOCKE, 1995, p. 279 [1690]). E também não falta a Locke o sentido da arbitrariedade das leis morais bem expressa quando diz que: "this rule being nothing but a collection of several simple ideas, the conformity thereto is but so ordering the action that the simple ideas belonging to it may correspond to those which the law requires" ${ }^{21}$. Mas noutros lugares da sua obra a que tive acesso através da obra de Raymond Polin, Locke é ainda mais conclusivo e afirma que:

"il y a, en effet, une autre sorte de moralité dont les règles ne sont pas de notre fabrication, auxquelles nous nous bornons à donner des noms, mais qui dépendent «upon something without us, and so not made by us, but for us», - de quelque chose qui est sans nous et qui, par conséquent n'a pas été fait par nous, mais pour nous. Ce sont les règles assignées à nos actions «by a lawgiver to all mankind", par un être autre que nous, capable de donner des lois à l'humanité entière et disposant du pouvoir de punir nos manquements. Ces règles se ramènent à la loi de la nature, qu'elle soit notifiée à l'homme par la lumière naturelle, ou par la révélation, et ce pouvoir supérieur est Dieu lui-même source directe ou indirecte de toute obligation en nous" ${ }^{22}$.

${ }^{20}$ É o que diz por exemplo Stephen Darwall: "Locke makes clear in a variety of places that he takes relation to God's law, and hence to His superior authority, to be necessary not just for moral obligation, but for morality to exist in any fashion at all", in DARWALL 1995: 35. E acrescenta que a racionalidade de que os homens são dotados tem um sabor pragmático no sentido em que Locke pensa que a única forma pela qual Deus pode fazer as suas exigências é através do facto de proporcionar aos agentes motivos racionais para lhes obedecer. Os agentes obedecem assim sempre a Deus, quer quando obedecem às leis, quer quando seguem as etapas do seu practical reasonimg.

${ }^{21}$ LOCKE 1995: 283 [1690]. Não admira. O cap. XXVIII do Livro II é occamista do princípio ao fim. É a parte da obra em que Locke desconstrói o realismo e defende o nominalismo com cópia de argumentos.

${ }^{22}$ POLIN 1960: 55. A ideia de bem associada à conformidade com a lei divina, da qual se infere a externalidade tanto no plano do fundamento quanto no plano das obrigações, está também desenvolvida no Essay concerning human understanding, Livro II, ao longo do cap. XXVIII. 
Só isso já seria suficiente para haver a certeza de que a suspensão lockeana não é nunca uma suspensão do juízo teorético à maneira dos céticos, uma vez que este argumento é pelo contrário um poderoso argumento contra o pirronismo. Mas, e isso é muito interessante, Locke não o faz negando o que no ceticismo é substantivo, quer dizer a nossa incapacidade estrutural para o conhecimento, mas operando uma torsão no sentido da epistemologia para a ontologia, querendo dizer que o que mais nos deve preocupar não é o que podemos ou não conhecer teoreticamente falando, mas o poder que temos para governar a nossa vida do ponto de vista existencial.

E o mais sugestivo ainda é que é neste argumento contra o ceticismo que se desenha o ceticismo larvar que existe em Locke e sobretudo que é através dele que Locke começa a construir o seu voluntarismo positivista, porque aí se intui uma dimensão do saber e do conhecimento que preexiste à dimensão estritamente humana, e ainda porque aí se pressupõe uma dimensão do conhecimento que é interdita ao homem.

O cap. XXI do Livro II intitula-se justamente, power, e eu não posso deixar de pensar imediatamente que este poder de que Locke fala neste capítulo, consiste, na circunstância, de uma delimitação do que está ou não no nosso poder, bem na linha do pensamento estóico, ou seja no eph' hemin grego e no ad manum est, quod sat est latino, provavelmente muito mais o latino, na medida em que no ecletismo latino, estoicismo e epicurismo já se aproximaram o suficiente para não serem orientações existenciais e morais antagónicas e contraditórias. Este capítulo é assim de uma inportância enorme na economia do pensamento de Locke porque é nele que se traçam as linhas mestras da autonomia humanista, mas também o primeiro esboço das linhas da não autonomia. É nesse deslindar do que está ou não está em nosso poder, poder esse já remetido a uma dimensão essencialmente ontológica e existentiva, que Locke encontrará os ingredientes sólidos de um internalismo autonomista, mas também os indícios do externalismo próprio do voluntarismo positivista. Num determinado momento eu intuí que o externalismo tinha por força que estar na obra de Locke e noutro momento acabei por concluir que estava lá inevitavelmente. Vou mostrar como.

Há que reconhecer que Locke não vai além de indícios, isto é, fazendo jus ao seu conceito nuclear de uneasiness, ele não exprimirá mais do que um desconforto pelas contradições que o tema do internalismo autonomista lhe sugere. Na sequência desse desconforto insinuará aquilo que se lhe afigura a solução, mas não a desenvolve, de resto nem chegará mesmo a abordá-la de uma forma inequívoca. Mas para mim esses indícios e a consciência das contradições é até mais importante do que tudo o que acabará por dizer de forma mais clara sobretudo na sua obra sobre a lei natural. Vamos ao assunto.

Apesar de Locke ter enfatizado ao longo de muitas páginas, duas questões, aliás complementares, a questão da felicidade e a questão da suspensão dos desejos, começa 
nos parágrafos finais do cap. XXI a introduzir uma nota de menor confiança, tanto nos objectivos quanto no método. Eu diria que até ao $\S 53$ não há verdadeiramente nenhuma dissonância. A convergência resume-se assim:

- Ponto 1. A felicidade, ou melhor a procura da felicidade, é a maior perfeição de natureza intelectual. A inclinação e a tendência para a felicidade constituem uma verdadeira obrigação moral. A felicidade é o que se procura obter em todas as ações. Toda a força do desejo é mobilizada para a obtenção da felicidade etc.

- Ponto 2. Os homens dispõem de um poder para lograr o seu grande objectivo, ou seja, a felicidade. Esse poder é o poder de suspender os desejos (eu diria os desejos e as ações), e assim ordenar a consideração das ideias. Esse poder é a expressão da liberdade do agente, ou seja, a liberdade de realizar ou suspender, para pensar melhor e realizar mais tarde de modo mais avisado. Ao suspender os desejos e as ações fica a mente em condições de reconsiderar a finalidade desses mesmos desejos e de os reexaminar sob todas as perspectivas possíveis, sem precipitação.

- E em jeito de síntese que enlaça os dois momentos: é pelo exercício dessa suspensão prudencial e calculante que se tranquiliza a consciência, uma vez que o que está em jogo é o maior bem que o agente pode alcançar, a saber, a sua felicidade. Até porque, e convém não esquecer, a felicidade significa o abandono completo do sofrimento ${ }^{23}$. À boa maneira epicurista.

Entretanto tudo se começa a complicar. Primeiro é o problema das perturbações extremas que podem ser induzidas pelas paixões. O simples poder de suspensão ao qual não faltava nem trabalho nem responsabilidades na resolução prudente das situações normais, digamos assim, vê-se agora a braços com trabalhos de Hécules, uma vez que deve meter ombros à responsabilidade de moderar e reprimir as paixões, o que desde a filosofia antiga era considerado um labor muito difícil. Diz-se que as paixões obnibulam o próprio entendimento, daí que se compreenda que não fui irônico ao considerar hercúlea a sua lide. Ou elas não existem e não são nenhum problema ou estão presentes e logo impedem a resolução intelectual das situações.

Depois há a ingente dificuldade, abundantemente glosada, tanto na literatura pagã como na religiosa, do conflito de faculdades ${ }^{24}$. No nosso caso concreto a glosa

${ }^{23}$ Como diz Locke: "For during this suspension of any desire, before the will be determined to action, and the action (which follows that determination) done, we have opportunity to examine, view, and judge of the good or evil of what we are going to do; and when upon due examination we have judged, we have done our duty, all that we can or ought to do in pursuit of our happiness; and it is not a fault but a perfection of our nature to desire, will and act, according to the last result of a fair examination", in Locke 1995: 185 [1690].

${ }^{24}$ Neste conflito ancestral entre o «Je-veux et le Je-non-veux», " I'issue ne peut dépendre que d'une action - si les Obras ne comptent plus, la Volonté est paralysée. Et puisque le conflit se place entre velte et nolte, la persuasion n'entre pas en ligne de compte, comme elle le faisait dans la vieille querelle entre raison et appétits. Car l'état de choses par lequel «le bien que je veux, je ne le fais pas, mais le mal que je ne veux pas, je le pratique» (in Romanos, $7,19)$ n'est pas nouveau, c'est bien évident. On retrouve presque le mot-à- mot dans Ovide: «Video meliora proboque, 
lockeana afirma que os homens desejam a felicidade, mas que pela vontade são muitas vezes conduzidos à infelicidade e ao mal. É o clássico conflito entre a razão e a vontade. Eu sei o que é o bem e decido-me pelo mal. Eu sei qual é o melhor caminho para atingir a felicidade e meto-me por atalhos. Às vezes mais ainda do que meter-me por atalhos eu meto mesmo os pés pelas mãos, quando afinal tudo parecia tão claro.

Depois há ainda o conflito das temporalidades. A felicidade a curto prazo pode colidir com a felicidade a longo termo, ou vice-versa. Como resolver o conflito. Que opção tomar, quando não se possuem outras referências senão a pulsão imediata e uma vaga esperança calculada pela razão. E se o curto prazo traz prazeres em abundância e mil remunerações, o longo prazo oferece para já sacrifícios e renúncias em troca de qualquer coisa duvidosa. É óbvio que o futuro mais tarde ou mais cedo, às vezes mais depressa do que parecia, torna-se presente, e quando Deus quer, um presente envenenado porque não foi sábia e pacientemente preparado. $O$ remoto só é remoto até ao momento em que se torna presente. Mas convenhamos que a gestão do que está ausente é muito mais complicada do que aquilo que se oferece imediatamente como fonte de uneasiness. De algum modo faz parte da natureza da intranquilidade (insatisfação, mal-estar) a sua imediateza e a sua presentificação. Faz parte da natureza ontológica da uneasiness um excesso ôntico, uma excessiva concreticidade existencial, que desfavorece o trabalho da suspensão estrutural. O Dasein atua na conjuntura sob a pressão do seu próprio desconforto ôntico, mas também ontológico.

Finalmente, por outro lado ainda, a noção do que é o bem e do que é o mal em face da definição de Locke, relativista e hedonista, varia de pessoa para pessoa e nem vale a pena inventariar casos e situações. E querendo ou não a verdade é que nos vamos, quer dizer Locke vai-se circunscrevendo a uma felicidade limitada e até precária.

O parágrafo sessenta é o momento de viragem. E pela primeira vez neste capítulo sobre o poder, coloca-se a possibilidade da necessidade de Deus. Repare-se que se está em sede não teológica. O cap. XXI tinha tudo para ser o lugar do triunfo do humanismo autonomista em Locke. As dificuldades apressaram as coisas. Vale a pena sublinhar:

"Change but a man's view of these things; let him see that virtue and religion are necessary
to his happiness; let him look into the future state of bliss or misery, and see their God the
righteous Judge ready to «render to every man according to his deeds; to them who by patient
continuance in welldoing seek for glory, and honour, and immortality, eternal life; but unto
every soul that doth evil, indignation and wrath, tribulation and anguish»; to him, I say, who

deteriora sequor (je vois le bien et je l'approuve, et c'est au mal que je me laisse entrâner), cf. Ovídio [As Metamorfoses], in CHAMONARD 1966: 177, et c'est sans doute une traduction du fameux passage de Médée d'Euripide (vers 1078-1080) «Oui, je sens le forfait que je vais oser; mais la passion [thymos, ce qui me meut] l'emporte sur mes résolutions [bouteumata], et c'est elle qui cause les pires maux aux humains». Euripide et Ovide déploraient peut-être la faiblesse de la raison face à l'élan passionné des désirs, et Aristote a sans doute franchi un pas de plus et pressenti une contradiction en soi dans le choix du pire, acte auquel il emprunte sa définition de «l'homme pervers», mais aucun d'entre eux n'aurait attribué ce phénomène au libre choix de la Volonté", in ARENDT 1983: 87. 
hath a prospect of the different state of perfect happiness or misery that attends all men after this life, depending on their behaviour here, the measures of good and evil that govern his choice are mightily changed. For, since nothing of pleasure and pain in this life can bear any proportion to endless happiness or exquisite misery of an immortal soul hereafter, actions in his power will have their preference, not according to the transient pleasure or pain that accompanies or follows them here, but as they serve to secure that perfect durable happiness hereafter" (LOCKE, 1995, p. 192 [1690]).

Não está longe o dispositivo das remunerações e das penas. No parágrafo setenta chama-se a atenção para isso tal como de resto no texto que citei, mas os argumentos são tênues e fazem ainda apelo da capacidade racional dos agentes. O dispositivo repressivo, a pastoral do medo associada ao voluntarismo teológico e jurídico completo, virá mais tarde.

Nos Concernings o dispositivo ganha clareza e torna-se mesmo apelativo.

"Once it has been granted that some divine power presides over the world something it would be impious to doubt, for he has commanded the heavens to turn in their perpetual revolution, (...) and all creatures in their obedience to his will have their own proper laws governing their birth and life; and there is nothing in all this world so unstable, so uncertain that it does not recognize authoritative and fixed laws which are suited to its own nature - once this has been granted it seems proper to ask if man alone has come into this world entirely outside some Jurisdiction, with no law proper to him, without plan, without law, without a rule for his life" (HORWITZ, 1990, p. 95 a 97).

E é nos Concernings que finalmente se encontra a lógica da rejeição do modelo intuicionista e a apologia fundamentada do externalismo radical e heterônomo de Locke. Desde o princípio que se adivinha sob a capa de uma promoção de uma racionalidade puramente instrumental e atávica uma suspeita relativamente à razão teorética. A promoção do sensismo já exprimia isso inequivocamente, Mas Locke é eloquente e o seu argumento esclarecedor.

"This law of nature can, therefore, be so described [as a law] because it is the command of the divine will, knowable by the light of nature, indicating what is and what is not consonant with a rational nature, and by that very fact commanding or prohibiting. Less accurately, it seems to me, some say (Grotius) it is a dictate of reason, for reason does not so much lay down and decree this law of nature as it discovers and investigates a law which is ordained by a higher power and has been implanted in our hearts. Nor is reason the maker of this law, but its Interpreter - unless we are willing to diminish the dignity of the supreme lawgiver and attribute to reason that received the law which it only investigates. Nor can reason, since it is only a faculty of the mind and a part of us, give us laws" (HORWITZ, 1990, p. 95 a 97).

O motivo pelo qual a razão não pode dar-nos leis é porque ela é apenas uma faculdade do espírito. Ela é apenas uma parte de nós. O carácter apodíctico deste argumento mostra o externalismo congénito de Locke. $O$ ente não pode dar-se leis a si mesmo. $\mathrm{O}$ esquema pressupõe sempre duas entidades, uma que dá e outra que recebe. A ideia de autonormatividade é incompreensível para Locke. Esta proposição deveria 
ser suficiente para não alimentar ambiguidades acerca do autonomismo lockeano, ou melhor, da falta dele. Para ele, a lei não pode ser produzida pelo homem internamente pelo que lhe basta dizer que a razão é uma faculdade do nosso espírito para se descartar sumariamente da possibilidade de o dador da norma (lei) ser a razão, que é o mesmo que dizer, o homem.

Mas também não é menos óbvio que a rejeição da razão não é meramente intelectual e que, embora numa linguagem moderada e contida, se pressente um certo rancor relativamente não propriamente à razão mas à presunção humanista de que a razão pudesse ter os poderes que pelo humanismo lhe são adjudicados. $E$ isso é fruto das raízes calvinistas da formação religiosa de Locke, que deixa transparecer o incômodo que a razão representa quando diz "unless we are willing to diminish the dignity of the supreme lawgiver" (p. 101).

É isso o que desde sempre impregnou o sensismo, a certeza de que não existe no horizonte das faculdades humanas nada que possa desempenhar um papel alternativo à omnipotência e à omnisciência divina. O que é odioso no humanismo intelectual racionalista é o desproporcionado papel conferido à razão, já que, por um lado, ele confere autonomia e capacidade de autogoverno e, por outro lado, insinua a capacidade de construir artificialmente uma Mathesis Universalis alternativa à gnoseologia e à ontologia teológico-religiosa.

E o modelo por excelência da lei é a lei divina, que em caso de não acesso à revelação se oferece ao homem através da luz natural. E sobre essa lei diz o autor que: "without the law of nature there would be no virtue or vice, no praise for probity or punishment for wickedness; where there is no law [there would] no wrong, no guilt" (p. 117). 0 credo de fé no externalismo positivista e a rejeição categórica do modelo intuicionista regressam ao ponto de partida.

E se Locke diz, mais à frente, que o conhecimento por natureza significa "nothing but the kind of true whose knowledge man can, by the right use of those faculties with which he is provided by nature", logo acrescenta que esse conhecimento se realiza a partir de noções primeiras, as quais "are not known by reason, for either they are impressed on our minds by inscription, or we receive them through tradition, or they enter through the senses. For reason, that great faculty of argumentation, does nothing unless something has been established and agreed to beforehand" (p. 111).

Até que finalmente é a apoteose da vontade. Em dois andamentos:

a. O reconhecimento de um legislador que detém o poder de submeter e que o faz através da lei.

b. Importante e decisivo: "We must also know that there is some will of that superior power as regards the things we must do; that is, that that legislator, whoever he may prove to be, wills us to do this, or to refrain from that, and demands of us that the conduct of our life be in agreement with his will" (p. 159). 
Isso em ordem a mostrar quais os limites da razão e dos sentidos no seu trabalho coordenado de condução do conhecimento da lei natural. Bem. Os limites são quase totais. Quer dizer, os sentidos e a razão podem trabalhar em conjunto no conhecimento da lei natural desde que saibam que antes já existe uma lei que nos condiciona absolutamente, que essa lei pressupõe um legislador que nos submete à sua vontade, através de um inelutable power, e que - não está aqui mas está noutros pontos da obra nos pode forçar à obediência através de rewards and punishments. E por fim que esse legislador já determinou o modo como se deve agir e não agir. E que devemos conduzir a nossa vida de acordo com a sua vontade. Enfim a margem de autonomia é mínima.

Aquilo que estava anunciado e esboçado no cap. XXI do Ensaio sobre o entendimento humano desenvolve-se no mesmo livro, mais à frente, no cap. XXVIII. E não deixa de ser sintomático que o autor para passar definitivamente à explanação do seu voluntarismo teológico, jurídico e moral, tenha necessidade de voltar a reintroduzir a sua propedêutica sensista e hedonista. Assim começa por definir o bem e o mal moral a partir do prazer e da dor:

"Good and evil, as hath been shown (book II, cha. XX, sect. 2, and chap. XXI, sect. 42), are nothing but pleasure or pain, or that which occasions or procures pleasure or pain to us. Moral good and evil, then, is only the conformity or disagreement of our voluntary actions to some law, whereby goof and evil is drawn on us from the will and power of the lawmaker; which good and evil, pleasure or pain, attending our observance or breach of the law, by the decree of the law-maker, is that we call «reward» and "punishment»" (LOCKE, 1995, p. 279 [1690]).

Para Locke o fato de que os agentes dispõem de uma racionalidade prática e uma liberdade para agir no quadro do seu interesse próprio, que é a procura da felicidade, não é suficiente. Afinal a ação livre dos homens é sempre acompanhada de regras que no fim de contas a superintendem e as regras não fariam sentido se não fossem acompanhadas de imposições axiológicas e normativas. Por outro lado, tanto as regras, como a normatividade que encerram, seriam vãs e fúteis se não contivessem explícita ou implicitamente recompensas e castigos. "It would be in vain for one intelligent being to set a rule to the actions of another, if he had it not in his power to reward the compliance with, and punish deviation from, his rule by some good and evil that is not the natural product and consequence of the action itself" (p. 279 e 280).

Aquilo que eu pretendo estabelecer como nexo de causalidade recíproca está todo aqui. Não é tanto o carácter repressivo e autoritário da consciência moral lockeana, fruto evidente do hiperaugustinianismo da sua formação calvinista. Não é tanto a antropologia pessimista e sombria em que se fundamenta, mas essencialmente o nexo causal entre essa antropologia, o sensismo e o hedonismo larvar. É tudo muito ilusório. A enfatização do prazer e da dor no sensismo e no empirismo lockeano não são afinal nem epicuristas nem cirenaicos. É na percepção da sua originalidade que reside a 
capacidade de compreensão do carácter não autonomista e não humanista deste tipo de posição. A propedêutica do prazer e da dor naturalmente sofrido só existe para que se desenvolva no final numa lógica do prazer e da dor infligido artificialmente, isto é, por uma entidade externa, exterior. A sua utilização é portanto totalmente pragmática. É a lógica anti-humanista do pecado global e da necessidade do castigo associada à convicção de uma profunda falibilidade das faculdades humanas que alimenta as suas posições. $\mathrm{E}$ isso também reforça o anti-humanismo e a heteronomia, que concebe o dispositivo das remunerações e das penas. Se por acaso o prazer e a dor não desempenhassem o papel que desempenham na propedêutica moral, como é que o autor poderia desenvolver uma lógica dos enforcements? O que é que seria suficientemente forte para obrigar? Uma vez que falham as capacidades propriamente humanas fica a repressão. A obrigação em Locke é duplamente anti-humanista. É anti-humanista porque é externa e é anti-humanista porque pressupõe a falência da razão e da vontade. Na situação pós-lapsária as faculdades humanas encontram-se praticamente destruídas (A razão prática não, pelo menos em Locke). Através delas o homem não será capaz de encontrar o seu rumo. O homem é mau tal como em Hobbes etc. A única forma de conceber uma orientação global para o bem implica leis, quer dizer regras, ditadas por uma entidade transcendente, essa sim sábia e boa. Para a imposição da sua vontade soberana precisa esse ser de um dispositivo repressivo que condicione e obrigue à obediência. Para que o prazer e a dor possam ser esse dispositivo é necessário que previamente se tenha mostrado a importância radical da dor e do prazer tanto no plano sensível quanto no plano moral. Já tinha acontecido com Hobbes, no fim de contas a dor é o medo da morte violenta.

Há três tipos de leis: as divinas, as civis e as leis de opinião ou reputação. As primeiras estão sob a alçada divina direta e portanto à la longue subordinadas à lógica dos rewards and punishments. Elas foram promulgadas pela revelação e(ou) pela luz natural, pelo que as leis da natureza se subsumem segundo Locke nas leis divinas. Quer isto dizer o que já referi atrás: "That God has given a rule whereby men should govern themselves, I think there is nobody so brutish as to deny" (p. 280). E veja-se mais uma vez o fundamento último dessas leis, da sua positividade e da sua força coerciva. "He has a right to do it; we are His creatures (...) He has power to enforce it by rewards and punishments, of infinite weight and duration, in another life (...) This is the only true touchstone of moral rectitude" (p. 280).

As segundas, as leis civis, são concebidas à imagem e semelhança das primeiras. A homologia é perfeita. As terceiras possuem uma importância muito relativa. Elas são muito desvalorizadas pelo autor, dada a sua relatividade, por um lado, mas sobretudo pela inexistência de mecanismos repressivos de coação. Até que finalmente as reconduz às leis divinas. Só através de uma vontade autoritária e legisladora as regras ganham eficácia, mas também consistência lógica. 


\section{REFERÊNCIAS}

AFONSO COSTA, M.. A ideia de felicidade em Portugal no século XVIII entre as Luzes e o Romantismo. Eticidade, moralidade e transcendência, Lisboa: Ed. Policopiada, 2008.

BURNS, J. H. (Ed.). The Cambridge history of political thought (3 Vols.), Cambridge: Cambridge University Press, 1991.

BURNS, J. H. (Ed.). Histoire de la pensée politique moderne, Paris: Presse Universitaires de France, 1997.

CANTO-SPERBER, Monique (Dir.). Dictionnaire d'éthique et de philosophie morale, Paris: Presses Universitaires de France, 1997.

DARWALL, Stephen. The british moralists and the internal 'ought' (1640-1740), Cambridge: Cambridge University Press, 1995.

EPICURO CONCHE, Marcel (Coord.). Épicure: Lettres et maximes, Paris: Presses Universitaires de France, 1992.

FORTE, João. Epicuro: Carta sobre a felicidade, Lisboa: Relógio d'Água, 1994.

GERT, Bernard (Ed.). Thomas Hobbes: Man and citizen, de homine and de cive, Indianapolis: Hackett Publishing Company. [1650], 1993.

HAAKONSSEN, Knud. Natural law and moral philosophy, from Grotius to the scottish enlightenment, Cambridge: Cambridge University Press, 1996.

HESPANHA, António Manuel. Panorama do pensamento jurídico-político europeu, Lisboa: EuropaAmérica, 1997.

HIBLER, Richard W. Happiness through tranquility. The school of Epicurus, Boston: University Press of America, 1984.

HOBBES FLATHMAN, Richard e David Johnston (Ed.). Thomas Hobbes: Leviathan, Londres: Norton. [1651], 1997.

HOBBES, Thomas. De Cive: «Philosophical rudiments concerning government and society», in Schneewind, J. B. (Ed.). Moral philosophy from Montaigne to Kant (2 Vols.), Cambridge. [1650], 1995.

LOCKE HORWITZ, Robert, e outros autores (Ed.). John Locke: Questions concerning the law of nature, Ithaca: Cornell University Press. [1664], 1990.

LOCKE, John. John Locke: The second treatise on civil government, Nova Iorque: Prometheus Books. [1689], 1986.

LOCKE, John. John Locke: A letter concerning toleration, Buffalo, Nova Iorque: Prometheus Books. [1689], 1990.

LOCKE, John. John Locke: Essay concerning human understanding, Nova Iorque: Prometheus Books. [1690], 1995.

MACPHERSON, C.B. La théorie de l'individualisme possessif. De Hobbes a Locke, Paris: Éditions Gallimard, 1971.

PIOVANI, Pietro. Giusnaturalismo ed etica moderna, Bari: Laterza, 1961. 
POLIN, Raymond. Politique et philosophie chez Thomas Hobbes, Paris: Presses Universitaires de France, 1953.

POLIN, Raymond. La politique moral de Johm Locke, Paris: Presses Universitaires de France, 1960.

POLIN, Raymond. Le bonheur considéré comme une des beaux-arts, Paris: Presses Universitaires de France, 1965.

SCHNEEWIND, J. B. The invention of autonomy. A history of modern moral philosophy, Cambridge: Cambridge University Press, 1998.

SELBY-BIGGE, L. A (Ed.). British moralists (2 Vols.), Oxford: Oxford Clarendon Press, 1897.

STRAUSS, Leo. Natural right and history, Chicago: University of Chicago Press, 1965.

TAYLOR, Charles. Sources of the self: The making of modern identity, Cambridge: Cambridge University Press, 1989.

THIEBAUT, Carlos (Ed.). La herencia ética de la ilustración, Barcelona: Editorial Crítica, 1991.

TONNIES, Ferdinand (Ed.). Thomas Hobbes: The elements of law natural et politic, Londres: Frank Cass. [1640], 1984.

TUCK, Richard. Natural rights theories, Cambridge: Cambridge University Press. [1979], 1998.

VILLEY, Michel. La formation de la pensée juridique moderne. Cours d'histoire de la philosophie du droit, Paris: Les Éditions Montchrestien, 1968.

WILLEY, Basil. The seventeenth century background, Nova Iorque: Columbia University Press, 1934.

WILLEY, Basil. The eighteenth century background, studies on the idea of nature in the thought of the period, Londres: Chatto \& Windus, 1949.

Recebido: dezembro 2010 Aprovado: abril 2011 
